\title{
Prevalence of cariogenic streptococci on incisor brackets detected by polymerase chain reaction
}

\author{
Sug-Joon Ahn, ${ }^{\text {a Bum-Soon Lim, }}{ }^{\mathrm{b}}$ and Shin-Jae Lee ${ }^{\mathrm{c}}$ \\ Seoul, Korea
}

Introduction: Streptococcus mutans and Streptococcus sobrinus are the main causative organisms for enamel demineralization during orthodontic treatment. In this study, we analyzed the prevalence of cariogenic streptococci adhering to incisor brackets. Methods: Four incisor brackets from both the maxilla and the mandible were collected from 80 patients at debonding, immediately after the visible plaque index and the gingival bleeding index were measured from the incisors. The genomic DNA of adhered cariogenic streptococci was extracted and amplified by using polymerase chain reaction, and the prevalence of cariogenic streptococci was determined and compared with oral hygiene indexes in the incisor area. Results: The results showed that the prevalence of $S$ mutans on incisor brackets was higher than that of $S$ sobrinus, and the maxillary incisor brackets were colonized by both cariogenic streptococci to a somewhat higher degree than were the mandibular brackets. The prevalence of $S$ mutans was $50.0 \%$ on the maxillary incisor brackets and $33.8 \%$ on the mandibular incisor brackets, but that of $S$ sobrinus was $17.5 \%$ and $15.0 \%$, respectively. At least 1 species of cariogenic streptococci was detected on the incisor brackets of 51 subjects $(63.7 \%)$. However, the prevalence of cariogenic streptococci was not significantly associated with the oral hygiene indexes at debonding. Conclusions: Cariogenic streptococci can adhere to orthodontic brackets. Careful hygiene control around orthodontic brackets is important. (Am J Orthod Dentofacial Orthop 2007;131:736-41)

$\mathbf{E}$ namel demineralization, or white spot formation, is a common side effect of orthodontic treatment with fixed appliances. The enamel demineralization in the maxillary incisor area can cause esthetic problems after orthodontic treatment. Enamel demineralization after therapy with fixed orthodontic appliances can occur in up to $50 \%$ of patients. ${ }^{1,2}$ Enamel demineralization is caused by organic acids produced mainly by mutans streptococci (MS), which are known to be the prime causative organism of dental caries. ${ }^{3-5}$ Of these species, $S$ mutans and $S$ sobrinus are the most frequently isolated from human oral cavities and have been implicated as the main causative organisms of dental caries. ${ }^{5,6}$

Among the many orthodontic appliances, brackets can play a key role in enamel demineralization because

\footnotetext{
From the School of Dentistry and Dental Research Institute, Seoul National University, Seoul, Korea.

aAssistant professor, Department of Orthodontics.

${ }^{\mathrm{b}}$ Associate professor, Department of Dental Biomaterials Science.

cAssociate professor, Department of Orthodontics.

Supported by Korea Research Foundation Grant funded by the Korean Government (KRF-2004-E00238).

Reprint requests to: Shin-Jae Lee, Department of Orthodontics, School of Dentistry and Dental Research Institute, Seoul National University, 28-22 Yunkeun-Dong, Chongro-Gu, Seoul 110-744, Korea (ROK); e-mail, nonext@ snu.ac.kr.

Submitted, May 2005; revised and accepted, June 2005.

0889-5406/\$32.00

Copyright (C) 2007 by the American Association of Orthodontists.

doi:10.1016/j.ajodo.2005.06.036
}

their complex designs increase the retention of food particles and dental plaque by impeding access to the tooth surfaces for cleaning. A previous report showed that extensive plaque accumulation is associated with bonded orthodontic brackets, ${ }^{7}$ and a fixed appliance with orthodontic brackets causes specific changes in the oral environment, such as decreased $\mathrm{pH}$ and increased plaque accumulation. ${ }^{8}$ The bacterial adhesion to orthodontic brackets can be the primary step leading to pathogenic plaque formation and enamel demineralization around orthodontic brackets, because the adhering bacteria continue to grow on the tooth surfaces near the brackets. In particular, metallic brackets are known to have the highest critical surface tension and have increased risk for enamel demineralization. ${ }^{9,10}$ This indicates that orthodontic brackets can impose a potential risk for enamel demineralization. Therefore, information on the prevalence of $S$ mutans and $S$ sobrinus on orthodontic metal brackets is helpful for identifying patients at risk of developing enamel demineralization and for planning caries-prevention programs during orthodontic treatment.

The isolation and identification of cariogenic streptococci has been based on the colonial morphology grown on mitis-salivarius-bacitracin agar. The isolated colonies are then identified by biochemical, immunologic, and genetic tests. ${ }^{11,12}$ However, these laboratory procedures can be inaccurate, time-consuming, and 


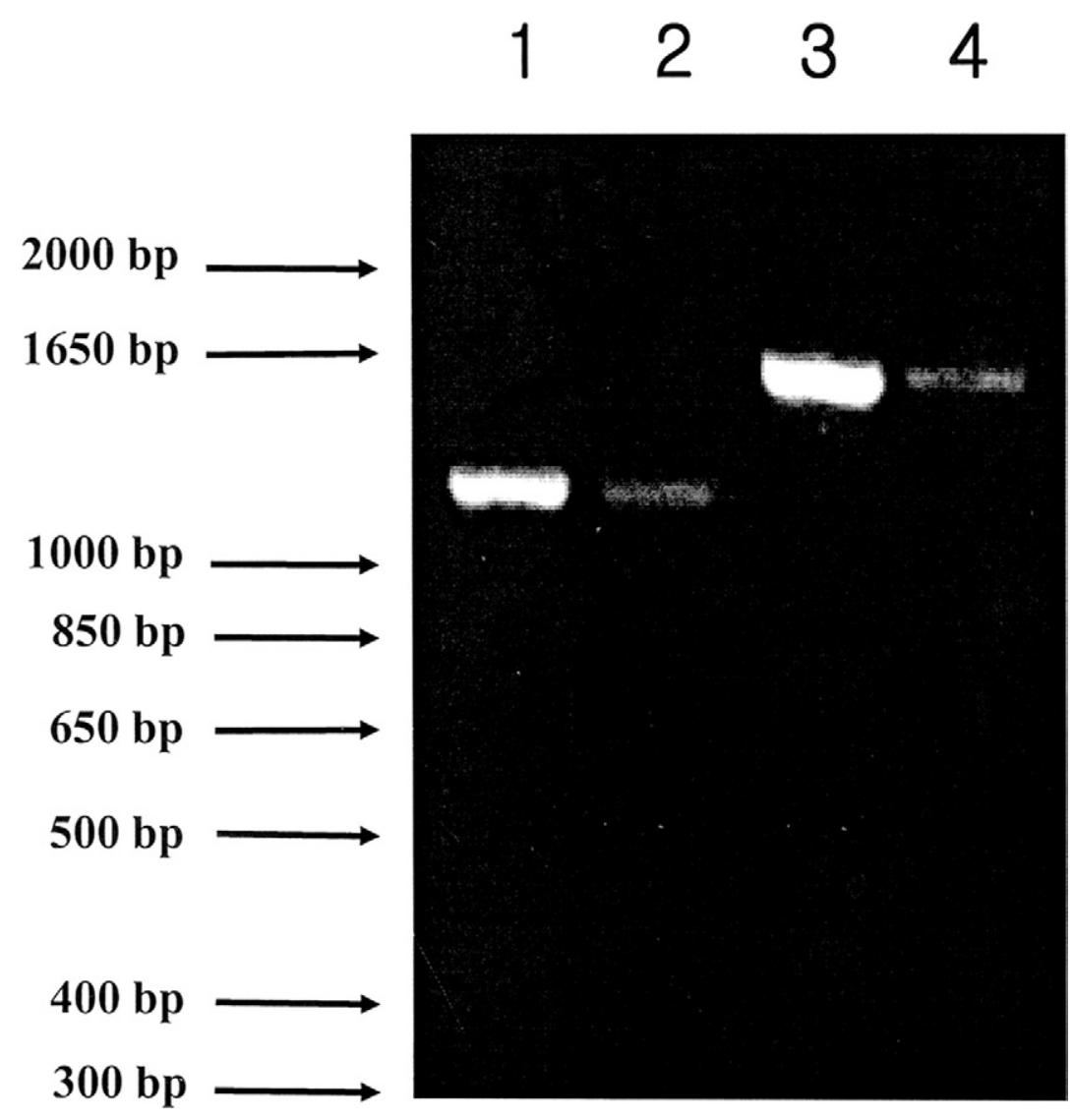

Fig. Sensitivity of dextranase PCR with purified chromosomal DNA from known numbers of $S$ sobrinus 6715 and $S$ mutans Ingbritt. Number of lysed cells in lanes: 1, 10,000 cells of $S$ mutans; 2, 1,000 cells of $S$ mutans; 3, 10,000 cells of $S$ sobrinus; 4, 1,000 cells of $S$ sobrinus. Chromosomal DNA extracted from as few as $1 \times 10^{3}$ cells of each species produced detectable PCR product.

laborious. Recently, new tools such as polymerase chain reaction (PCR) have been used to overcome these limitations. PCR is a simple, rapid, and highly specific method that uses specific DNA fractions for the detection and identification of microorganisms. ${ }^{13,14}$ The purpose of this study was to analyze the prevalence of cariogenic streptococci on incisor brackets in vivo and to evaluate the relationship between cariogenic streptococci and oral hygiene indexes in maxillary incisor regions with the specific PCR methods for $S$ sobrinus and $S$ mutans.

\section{MATERIAL AND METHODS}

Eleven strains of MS and other gram-positive streptococci (5 strains of 3 species) and gram-negative species (11 strains of 9 species) were used as positive and negative controls in PCR (data not shown). Grampositive bacteria were grown anaerobically at $37^{\circ} \mathrm{C}$ on brain-heart infusion (Difco Laboratories, Detroit, Mch) agar plates. Gram-negative bacteria were grown anaer- obically at $37^{\circ} \mathrm{C}$ on brain-heart infusion agar plates supplemented with $5 \%$ horse blood, hemin $(5 \mu \mathrm{g}$ per milliliter), and menadione (50 $\mu \mathrm{g}$ per milliliter).

Known specific primers that amplify the dextranase gene of $S$ mutans and $S$ sobrinus were selected. ${ }^{13,14}$ For $S$ mutans, the upper primer, 5'-TAT GCT GCT ATT GGA GGT TC-3', is complementary to the sequence 973 to 992 , and the lower primer, 5'-AAG GTT GAG CAA TTG AAT CG-3', is complementary to the sequence 2225 to 2244 . The size of expected PCR product was 1215 base pairs (bp) (Fig). The upper primer, 5'-TAC TAT CTT TCC CTA GCA TG-3', is complementary to the sequence 134 to 153 , and the lower primer, 5'-GGT ATT CGG TTT GAC TGC-3', is complementary to the sequence 1743 to 1726 for $S$ sobrinus. The size of expected PCR product was 1610 bp (Fig). All primers were commercially synthesized (Takara Korea, Seoul, Korea).

Eighty patients who had just completed fixed orthodontic therapy were selected for this study (average 
age at the beginning of treatment, 20.9 years; range, 15.2-45.2 years). They were treated with the same metal brackets (Victory series, 3M Unitek, Monrovia, Calif). The 4 maxillary and 4 mandibular incisor brackets were carefully removed and collected at debonding. The brackets were washed 3 times with sterile phosphatebuffered saline solution ( $\mathrm{pH}$ 7.4) and immediately used for extraction of chromosomal DNA from the adhering bacteria.

Chromosomal DNAs of the bacteria were extracted by a standard miniprep procedure, ${ }^{15}$ to which we added a lysozyme treatment. Briefly, bacterial cells were incubated at $37^{\circ} \mathrm{C}$ by $300 \mu \mathrm{L}$ of phosphate-buffered saline solution with 1000 units of lysozyme with agitation for 1 hour. After centrifugation at 12,000 $\mathrm{g}$ for 10 minutes, the supernatant was removed, and the cells were suspended with $300 \mu \mathrm{L}$ of lysis solution (10 $\mathrm{mmol} / \mathrm{L}$ Tris- $\mathrm{HCl}, 1 \mathrm{mmol} / \mathrm{L}$ of EDTA, $0.5 \%$ sodium dodecyl sulfate, $40 \mu \mathrm{g}$ of proteinase $\mathrm{K}, \mathrm{pH}$ 8.0) with agitation at $37^{\circ} \mathrm{C}$ for 1 hour. After the addition of $50 \mu \mathrm{L}$ of $5 \mathrm{~mol} / \mathrm{L}$ sodium chloride and $40 \mu \mathrm{L}$ of $4 \%$ cetyltriammonium bromide, the suspension was incubated at $65^{\circ} \mathrm{C}$ for 10 minutes. The resultant lysate was extracted with phenol-chloroform and precipitated with isopropyl alcohol. All DNA fractions were then stored in $30 \mu \mathrm{L}$ of Tris-EDTA buffer $(10 \mathrm{mmol} / \mathrm{L}$ of Tris- $\mathrm{HCl}$ buffer, 1 $\mathrm{mmol} / \mathrm{L}$ of EDTA, $\mathrm{pH}$ 7.4). Extraction of chromosomal DNA from the reference bacteria was performed in the same way.

Each PCR mixture $(50 \mu \mathrm{L})$ consisted of $10 \mathrm{mmol} / \mathrm{L}$ Tris-HCl buffer ( $\mathrm{pH}$ 8.3), $1.5 \mathrm{mmol} / \mathrm{L} \mathrm{MgCl}_{2}, 50$ $\mathrm{mmol} / \mathrm{L} \mathrm{KCl}, 200 \mu \mathrm{M}$ each of dATP, dTTP, dGTP, and $\mathrm{dCTP}, 1 \mu \mathrm{M}$ oligonucleotide primers of both $S$ mutans and $S$ sobrinus, 2.5 units of Taq DNA polymerase (Takara-Korea), and $10 \mu \mathrm{L}$ of template solution. The mixture was denatured at $95^{\circ} \mathrm{C}$ for 3 minutes followed by a series of amplifications: denaturation at $95^{\circ} \mathrm{C}$ for 1 minute, annealing at $55^{\circ} \mathrm{C}$ for 1 minute, and extension at $72^{\circ} \mathrm{C}$ for 1 minute. The series was repeated for 32 cycles. The final cycle comprised $95^{\circ} \mathrm{C}$ for 1 minute, $55^{\circ} \mathrm{C}$ for 1 minute, and $72^{\circ} \mathrm{C}$ for 5 minutes. The amplified products were electrophoresed on $1.0 \%$ agarose gels and stained with ethidium bromide.

The visible plaque index (VPI) ${ }^{14}$ and the gingival bleeding index $(\mathrm{GBI})^{14}$ were used to assess the 4 incisors to examine the relationship between the oral hygiene indexes and cariogenic streptococci at debonding. One investigator (A.S-J.) recorded the VPI and the GBI on the mesiobuccal surfaces of the 4 incisors. The VPI was recorded as 1 for visible plaque and 0 for nonvisible plaque on the mesiobuccal surface of each tooth, after rinsing and drying the tooth surfaces. The GBI was assessed by using a $0.5-\mathrm{mm}$ diameter peri- odontal probe. Bleeding was recorded as 1 and no bleeding as 0 . Each index of the incisors was totaled, and the sum was used to represent each index. The results were compared with the prevalence of cariogenic streptococci on the incisor brackets.

\section{Statistical analysis}

To test how strongly the prevalence of cariogenic streptococci on the maxillary and mandibular incisor brackets is associated, the lambda coefficient of proportional reduction in error and the McNemar-Bowker test were used. Two-way ANOVA was used to analyze the relationship between cariogenic streptococci and oral hygiene. A $P$ value of less than .05 was considered significant.

\section{RESULTS}

The sensitivity of PCR was examined by using known numbers of cells of $S$ mutans Ingbritt and $S$ sobrinus 6715 . The total cell count of each strain was adjusted to 10,000 cells per milliliter by using a Petroff-Hauser counter (Hauser Scientific Partnership, Horsham, Pa). When chromosomal DNA extracted from serially diluted cell suspensions was used as the template for PCR, chromosomal DNA extracted from as few as 1000 cells of each strain produced a detectable PCR product (Fig).

Eleven strains of MS and other gram-positive streptococci (5 strains of 3 species) and gram-negative species (11 strains of 9 species) were examined by using the specific primer pairs to evaluate the specificity of PCR. Of the 11 strains of MS, only $S$ mutans and $S$ sobrinus produced single DNA fragments of $1272 \mathrm{bp}$ and $1610 \mathrm{bp}$, respectively. Amplified DNA was not found in other MS or in other gram-positive or gramnegative species (data not shown). These results suggest that the primers used in this study are specific for $S$ mutans or $S$ sobrinus.

The prevalence of the adhered cariogenic streptococci was determined on incisor brackets according to the results of PCR. A positive PCR response suggested that the number of streptococci adhering to the 4 incisor brackets was over 1000 cells. The modal category in Table I showed that no cariogenic streptococci were detected on either the maxillary or the mandibular incisor brackets in 29 patients $(36.3 \%)$. However, $S$ mutans was found on the maxillary brackets of 40 patients (50.0\%) and $S$ sobrinus in those of 14 patients $(17.5 \%)$. In the mandibular arch, $S$ mutans was found in 27 patients (33.8\%) and S sobrinus in 12 patients $(15.0 \%)$. The prevalence of cariogenic streptococci in the maxilla was significantly associated with that of the mandible; the symmetric lambda coefficient 
Table I. Prevalence of $S$ mutans and $S$ sobrinus on incisor metal brackets from 80 patients

\begin{tabular}{lccccc}
\hline & \multicolumn{5}{c}{ Maxilla (\%) } \\
\cline { 2 - 6 } & Absent & S mutans & $\begin{array}{c}\text { Sobrinus } \\
\text { Both }\end{array}$ & Total \\
\hline Mandible (\%) & & & & & \\
Absent & $29(36.3)$ & $15(18.8)$ & $1(1.2)$ & $1(1.2)$ & $46(57.5)$ \\
S mutans & $4(5.0)$ & $16(20.0)$ & $1(1.2)$ & $1(1.2)$ & $22(27.5)$ \\
S sobrinus & $0(0.0)$ & $2(2.5)$ & $4(5.0)$ & $1(1.2)$ & $7(8.8)$ \\
Both & $0(0)$ & $0(0)$ & $1(1.2)$ & $4(5.0)$ & $5(6.2)$ \\
Total & $33(41.3)$ & $33(41.3)$ & $7(8.8)$ & $7(8.8)$ & $80(100.0)$ \\
\hline
\end{tabular}

Table II. Relationship between prevalence of $S$ mutans and $S$ sobrinus and oral hygiene indexes on incisor brackets

\begin{tabular}{lcccc}
\hline S mutans & S sobrinus & $\begin{array}{c}\text { Number of } \\
\text { patients }\end{array}$ & $\begin{array}{c}\text { VPI } \\
(\text { mean } \pm S D)\end{array}$ & $\begin{array}{c}G B I \\
(\text { mean } \pm S D)\end{array}$ \\
\hline- & - & 33 & $0.39 \pm 0.96$ & $1.83 \pm 1.31$ \\
& + & 6 & $1.33 \pm 0.82$ & $2.83 \pm 1.17$ \\
& Subtotal & 39 & $0.54 \pm .95$ & $1.97 \pm 1.33$ \\
+ & - & 34 & $0.84 \pm 1.32$ & $1.81 \pm 1.28$ \\
& + & 7 & $1.04 \pm 0.89$ & $1.67 \pm 1.58$ \\
Total & Subtotal & 41 & $0.94 \pm 1.11$ & $1.78 \pm 1.33$ \\
& - & 67 & $0.62 \pm 1.17$ & $1.82 \pm 1.29$ \\
& + & 13 & $1.19 \pm 0.89$ & $2.13 \pm 1.51$ \\
& Total & 80 & $0.91 \pm 1.03$ & $1.89 \pm 1.33$ \\
\hline
\end{tabular}

Existence of cariogenic streptococci was expressed as - (nonexistence) and + (existence). Positive sign means that number of streptococci adhered to incisor brackets was over 1000 cells.

was $0.37(P<.01)$. The upper off-diagonal elements in Table I showed that the prevalence of cariogenic streptococci in the maxilla was greater than in the mandible $(P<.05)$.

Table II shows the relationship between the prevalence of cariogenic streptococci and the oral hygiene indexes of the 4 maxillary incisors at debonding. Two-way ANOVA showed no significant relationship between either streptococci and oral hygiene indexes. In addition, no interaction was found between the prevalence of $S$ mutans and $S$ sobrinus.

\section{DISCUSSION}

Plaque accumulating around orthodontic brackets even in patients with good oral hygiene often results in enamel white spot formation adjacent to the brackets. ${ }^{7}$ Nevertheless, there are few reports on the biologic aspects of the association between the existence and prevalence of cariogenic MS and orthodontic brackets in vivo. In this study, we aimed to examine the prevalence of cariogenic MS on incisor metal brackets of orthodontic patients.
We showed that the prevalence of $S$ mutans was $50.0 \%$ on maxillary incisor brackets and $33.8 \%$ on mandibular incisor brackets; the prevalence of $S$ sobrinus was $17.5 \%$ and $15.0 \%$, respectively (Table I). The prevalence on the brackets was significantly lower than that currently reported in the oral cavity. The prevalence of $S$ sobrinus was reported to be about $80 \%$ in human oral cavities and that of $S$ mutans to be $100 \%$ by using PCR. ${ }^{13,14}$ The low prevalence can be explained by the low binding affinity of cariogenic MS to orthodontic brackets. A previous study reported that the binding affinity of cariogenic streptococci to orthodontic metal brackets was under $0.5 \%$, and the adhesion amount was significantly lower than that of other streptococci. ${ }^{10}$

We also found a higher prevalence of $S$ mutans than of $S$ sobrinus on the incisor brackets (Table I). The prevalence of $S$ mutans was about 2 times higher than that of $S$ sobrinus. This is consistent with a previous study that showed that the binding affinity of $S$ mutans to orthodontic metal brackets was about 2 times higher than that of $S$ sobrinus. ${ }^{16-18}$ This difference in the prevalence between the 2 species could also be partly explained by fundamental differences in their prevalences in the oral cavity. Many studies have shown that $S$ mutans is isolated more frequently than $S$ sobrinus in the oral cavity. ${ }^{5,19}$

A difference in prevalence was also found between the maxillary and the mandibular incisor brackets. Both cariogenic streptococci colonized on the maxillary incisor brackets to a somewhat higher degree than those of the mandible (Table I). This result is consistent with another study that showed that MS is more prevalent in the anterior region of the maxillary arch than in the mandibular arch. $^{20}$ This might be explained by the presence of major salivary glands, which clear the mandibular anterior portion more rapidly than the maxillary portion because of easy access of saliva. The maxillary anterior region is located far from the major salivary glands and appears to receive little saliva. This can probably cause greater retention and slower elimination of food debris and sucrose, and provide better conditions for colonization of cariogenic MS. This could also explain why the maxillary incisors are more affected by enamel demineralization and white spot formation than the mandibular incisors during orthodontic treatment. ${ }^{20}$

Two-way ANOVA showed no significant relationship between the prevalence of both streptococci and the oral hygiene indexes (Table II). This means that oral hygiene status was not strongly associated with cariogenic streptococci in this area. This might be mainly because dental plaque contains many other bacteria rather than only cariogenic streptococci. A 
previous study showed that the proportion of $S$ mutans was significantly smaller than other oral bacteria and comprised only $0.5 \%$ of dental plaque after 24 hours. ${ }^{21}$ This was also explained by the high sensitivity of the PCR, which was so sensitive that it could diagnose as few as 1000 cells of $S$ mutans or $S$ sobrinus adhering to the 4 maxillary incisor brackets; this might be inadequate to influence oral hygiene around the brackets and the teeth. In addition, the sum of the plaque index in the 4 maxillary incisors was 0 in 56 patients. Their proper maintenance of oral hygiene could have contributed to the low prevalence and its insignificant association with oral hygiene indexes. Nevertheless, the plaque index seemed to be slightly associated with cariogenic streptococci, although there was no statistical significance. When the PCR result showed a positive response to at least 1 species of cariogenic streptococci, the plaque index tended to increase compared with subjects with a negative response.

The presence of $S$ mutans and $S$ sobrinus on orthodontic brackets might not predict caries development in orthodontic patients. However, cariogenic MS indicates that careful attention is required for the prevention of white spot formation or enamel demineralization, because both $S$ mutans and $S$ sobrinus were strongly correlated with early carious lesions. ${ }^{5}$ In particular, $S$ sobrinus was closely associated with increases in smooth-surface caries. ${ }^{22,23}$ This means that the presence of $S$ mutans and especially $S$ sobrinus on the anterior brackets indicates that orthodontic brackets might be a potential risk factor for enamel demineralization, particularly in orthodontic patients with poor oral hygiene or increased caries activity. Cariogenic streptococci on orthodontic brackets could allow the remaining bacteria on orthodontic brackets to continue to grow on tooth surfaces near the brackets, because microbial mass increases primarily as a result of cell division. ${ }^{24}$

This study provides information on the prevalence of cariogenic streptococci by using cariogenic bacteriaspecific PCR. The capability of PCR in detecting fewer than 1000 bacteria is sufficient to identify cariogenic streptococci around orthodontic brackets. Furthermore, the presence of $S$ sobrinus and $S$ mutans can be determined within a day (6-7 hours) because bacterial growth, isolation, and culture procedures are omitted. This study suggests the possibility of using PCR when patients who might be at risk of developing enamel demineralization need to be identified.

\section{CONCLUSIONS}

The prevalence of cariogenic MS adhering to incisor brackets in vivo was analyzed with oral hygiene indexes by using PCR. The results showed that the prevalence of $S$ mutans was about 2 times higher that that of $S$ sobrinus on incisor brackets. Both cariogenic streptococci colonized on maxillary brackets more than on mandibular brackets. However, the prevalence of cariogenic streptococci was not significantly associated with oral hygiene indexes in the maxillary incisor area. This study indicates that cariogenic MS might be a resident species on incisor brackets; this stresses the need for careful hygiene control around orthodontic brackets to prevent enamel demineralization. ${ }^{16,18}$

\section{REFERENCES}

1. Gorelick L, Geiger AM, Gwinnett AJ. Incidence of white spot formation after bonding and banding. Am J Orthod 1982;81: 93-8.

2. Årtun J, Brobakken B. Prevalence of caries and white spots after orthodontic treatment with multibonded appliances. Eur J Orthod 1986;8:229-34.

3. Chestnutt IG, MacFarlane TW, Stephen KW. An in vitro investigation of the cariogenic potential of oral streptococci. Arch Oral Biol 1994;39:589-93.

4. Featherstone JD. The science and practice of caries prevention. J Am Dent Assoc 2000;131:887-99.

5. Babaahmady KG, Challacombe SJ, Marsh PD, Newman HN Ecological study of Streptococcus mutans, Streptococcus sobrinus and Lactobacillus spp. at sub-sites from approximal dental plaque from children. Caries Res 1998;32:51-8.

6. Hamada S, Slade HD. Biology, immunology, and cariogenicity of Streptococcus mutans. Microbiol Rev 1980;44:331-84.

7. Gwinnett AJ, Ceen RF. Plaque distribution on bonded brackets: a scanning microscope study. Am J Orthod 1979;75:667-77.

8. Mitchell L. Decalcification during orthodontic treatment with fixed appliance - an overview. Br J Orthod 1992;19:199-205.

9. Eliades T, Eliades G, Brantley W. Microbial attachment on orthodontic appliances: I. Wettability and early pellicle formation on bracket materials. Am J Orthod Dentofacial Orthop 1995;108:351-60.

10. Ahn SJ, Kho HS, Lee SW, Nahm DS. Roles of salivary proteins in the adherence of oral streptococci to various orthodontic brackets. J Dent Res 2002;81:411-5.

11. Beighton D, Hardie JM, Whiley RA. A scheme for the identification of viridans streptococci. J Med Microbiol 1991;35:367-72.

12. Smorawinska M, Kuramitsu HK. DNA probes for detection of cariogenic Streptococcus mutans. Oral Microbiol Immunol 1992; 7:177-81

13. Igarashi T, Yamamoto A, Goto N. Direct detection of Streptococcus mutans in human dental plaque by polymerase chain reaction. Oral Microbiol Immunol 1996;5:294-8.

14. Igarashi $\mathrm{T}$, Yamamoto $\mathrm{A}$, Goto N. PCR for detection and identification of Streptococcus sobrinus. J Med Microbiol 2000; 49:1069-74.

15. Ausubel FM, Brent R, Kingston RE, Moore DD, Seidman JG, Smith JA, et al. Current protocols in molecular biology. In: Vol I. Preparation and analysis of DNA. Chapter 2. New York, NY: John Wiley \& Sons; 1998.

16. Ahn SJ, Lim BS, Lee YK, Nahm DS. Quantitative determination of adhesion pattern of cariogenic streptococci to various orthodontic adhesives. Angle Orthod 2006;76:867-73. 
17. Ahn SJ, Lim BS, Yang HC, Chang YI. Quantitative analysis of the adhesion of cariogenic streptococci to orthodontic metal brackets. Angle Orthod 2005;75:666-71.

18. Ahn S, Lee SJ, Lim BS, Nahm DS. Quantitative determination of adhesion patterns of cariogenic streptococci to various orthodontic brackets. Am J Orthod Dentofacial Orthop 2007 in press.

19. Wennerholm K, Emilson CG. Sucrose retention and colonization by mutans streptococci at different sites of the dentition. Caries Res 1995;29:396-401.

20. Arneberg P, Giertsen E, Emberland H, Ogaard B. Intra-oral variations in total plaque fluoride related to plaque PH. A study in orthodontic patients. Caries Res 1997;31:451-6.
21. Nyvad B, Kilian M. Comparison of the initial streptococcal microflora on dental enamel in caries-active and in cariesinactive individuals. Caries Res 1990;24:267-72.

22. de Soet JJ, van Loveren C, Lammens AJ, Pavicic MJ, Homburg $\mathrm{CH}$, ten Cate JM, et al. Differences in cariogenicity between fresh isolates of Streptococcus sobrinus and Streptococcus mutans. Caries Res 1991;25:116-22.

23. Madison KM, Bowen WH, Pearson SK, Falany JL. Enhancing the virulence of Streptococccus sobrinus in rats. J Dent Res 1991;70:38-43.

24. Brecx M, Theilade J, Attstrom R. An ultrastructural quantitative study of the significance of microbial multiplication during early dental plaque growth. J Periodontal Res 1983;18:177-86.

Editors of the International Journal of Orthodontia (1915-1918),

International Journal of Orthodontia \& Oral Surgery (1919-1921),

International Journal of Orthodontia, Oral Surgery and Radiography (1922-1932),

International Journal of Orthodontia and Dentistry of Children (1933-1935),

International Journal of Orthodontics and Oral Surgery (1936-1937), American

Journal of Orthodontics and Oral Surgery (1938-1947), American Journal of

Orthodontics (1948-1986), and American Journal of Orthodontics and Dentofacial

Orthopedics (1986-present)

1915 to 1932 Martin Dewey

1931 to 1968 H. C. Pollock

1968 to 1978 B. F. Dewel

1978 to 1985 Wayne G. Watson

1985 to 2000 Thomas M. Graber

2000 to present David L. Turpin 